\title{
Impediments to therapeutic advances for patients with gastroesophageal adenocarcinoma
}

Globally, gastroesophageal adenocarcinomas (GEAs) impose an enormous health burden. In most of the world, diagnosis is made based on symptoms and not potential risk. This leads to high number of cases with advanced cancer at diagnosis. Advanced GEA patients face especial challenges such as nutritional deficiency, anemia, low-grade chronic bleeding, peritoneal carcinomatosis, and ovarian metastases (in females) in conjunction with lack of effective therapeutic options. These tumors are inherently resistant to therapy (cytotoxics and immunotherapy) due to considerable tumor heterogeneity. Patients become more symptomatic during the course of their illness and subsequent therapies become less effective leading to the median overall survival of less than 1 year. We consistently disappoint our patients and their relatives who have high expectations of us. We don't seem to be able to deliver. A majority of this disappointment is due to lack of intensive research on GEA and some is due to complexity of advanced GEAs. Certain concepts are worth pondering on: (I) intra and inter tumor heterogeneity. Single cell DNA sequencing has highlighted immense heterogeneity among tumor cells. Acquisition of heterogeneity is essential for cancer cell survival. If all cancer cells had the same genomics, transcriptomics, epigenomics, and proteomics including surfaceome, and immunomics profiles then it would have been very easy for us to cure patients with advanced cancer. However, the evolved heterogeneity in cells of a single tumor suggests we must consider high-dimensional interrogations of tumors but also use most advanced technology and bioinformatics (including artificial intelligence) to get ahead. Therefore, tissue-based approaches (that are already least reliable) must be superseded by blood-based approaches (not just DNA but RNA, proteins and peptides, antibodies, exosomes, immune elements such as expanded clones of T-cells and B-cells, cytokines, etc.). One-time evaluation of molecular status of a patient's tumor is also insufficient and we must figure out which drivers are engaged at different times and different clones of cancer cells may be using different drivers (meaning multiple drivers at the same time but by different clones). Inter tumor heterogeneity means, we can no longer be empiric in recommending or investigating therapies (one treatment fits all) as we have been for more than 50 years. Every patient should be grouped based on molecular and immune profiles based on multiple platforms and multiple elements assessed of each tumor. (II) We should now pay attention to the emerging concept of adaptive resistance. This does not imply that acquired resistance (at the genomic and non-genomic levels) does not exist but the adaptive resistance appears to be the major tool for cancer cell survival. Adaptive resistance has been uncovered by sequential single cell DNA sequencing. It implies that multiple clones (at the DNA level) already exist in a given cancer (say for example the primary tumor or large metastasis). Some clones are expanded initially (this must be context-based) while others are hard to detect by more blunted interrogations (such as NGS or limited featured liquid biopsy). Once the expanded clone is depleted (by initial or subsequent active therapy) then more resistant pre-existing clones emerge (important to recognize that here there are no new mutations, indels, amplifications, etc. occurring). This process of pre-existing clones expanding depending on the context imposes another challenge to gain advantage for our patients. Introduce the concept of plasticity at many levels and we have a more complex challenge. Again, very detailed profiling would provide some insights. There are algorithms in place to predict drivers but they are based on bulk profiling and not single cell profiling. (III) Germline genomic information of a given patient may aid in deciphering therapeutic options for that particular patient; a concept that has not had much traction yet. A classic example is therapeutics based on BRCA1/2 germline mutations leading to impaired double-strand DNA break repair. Gratifyingly, some benefits are already being realized in ovarian cancer patients and breast cancer patients. Its benefit to pancreatic cancer patients is a subject of debate but does not jeopardize the principle that germline genomic information is not just for risk evaluation. (IV) The tumor microenvironment (TME) is often orchestrated by cancer cells (various oncogenes are well known to suppress the immune environment) and it is not an accident (exception would be the microsatellite instability leading to hypermutated phenotype of cancers where immune system is much more engaged that in microsatellite stable tumors; here the TME is under reduced control of the cancer cells but cancer cells can still survive this difficult position). Finally, (V) turning back to advanced GEAs, we still have a lot of work to do. Federal funds are limited. We are making very slow progress. Recognizing that many patients in the West are beginning to liver longer due to access to $3^{\text {rd }}$ and later line therapies. Also, access to sophisticated clinical trials. The expanding frontier of novel clinical trials that are innovative in engaging the immune system in a more sophisticated manner will provide a lot of advantage (cell therapies, vaccines, and combinations that target oncogenes and immune targets). Learning about microbiome and its impact of immune resistance $v s$. immune response. Patient and communities need to be educated for the need to donate research specimens generously and frequently. As a society, we should provide more funding for research on GEA to harness the powers of sophisticated technologies and talented investigators. The 
empiric medicine has to go although it has provided us some benefits but certainly far from what our patients need and expect.

\section{Acknowledgments}

Funding: None.

\section{Footnote}

Provenance and Peer Review: This article was commissioned by the editorial office, Translational Gastroenterology and Hepatology for the series "Gastrointestinal Cancer". The article did not undergo external peer review.

Conflicts of Interest: The author has completed the ICMJE uniform disclosure form (available at http://dx.doi.org/10.21037/ tgh.2020.03.07). JAA served as the unpaid Guest Editor of the series and serves as an unpaid editorial board member of Translational Gastroenterology and Hepatology from Apr 2019 to Mar 2021. The author has no other conflicts of interest to declare.

Ethical Statement: The author is accountable for all aspects of the work in ensuring that questions related to the accuracy or integrity of any part of the work are appropriately investigated and resolved.

Open Access Statement: This is an Open Access article distributed in accordance with the Creative Commons Attribution-NonCommercialNoDerivs 4.0 International License (CC BY-NC-ND 4.0), which permits the non-commercial replication and distribution of the article with the strict proviso that no changes or edits are made and the original work is properly cited (including links to both the formal publication through the relevant DOI and the license). See: https://creativecommons.org/licenses/by-nc-nd/4.0/.

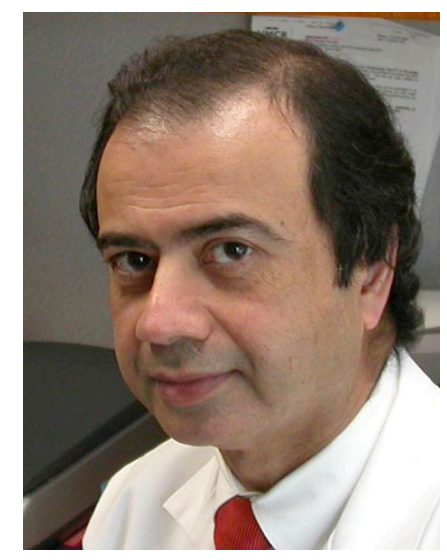

Jaffer A. Ajani 
Jaffer A. Ajani, MD

Department of Gastrointestinal Medical Oncology, University of Texas MD Anderson Cancer Center,

Houston, TX, USA.

(Email:jajani@mdanderson.org)

Received: 16 March 2020; Accepted: 30 March 2020; Published: 25 July 2021.

doi: $10.21037 / \operatorname{tgh} .2020 .03 .07$

View this article at: http://dx.doi.org/10.21037/tgh.2020.03.07

doi: $10.21037 / \operatorname{tgh} .2020 .03 .07$

Cite this article as: Ajani JA. Impediments to therapeutic advances for patients with gastroesophageal adenocarcinoma.

Transl Gastroenterol Hepatol 2021;6:49. 